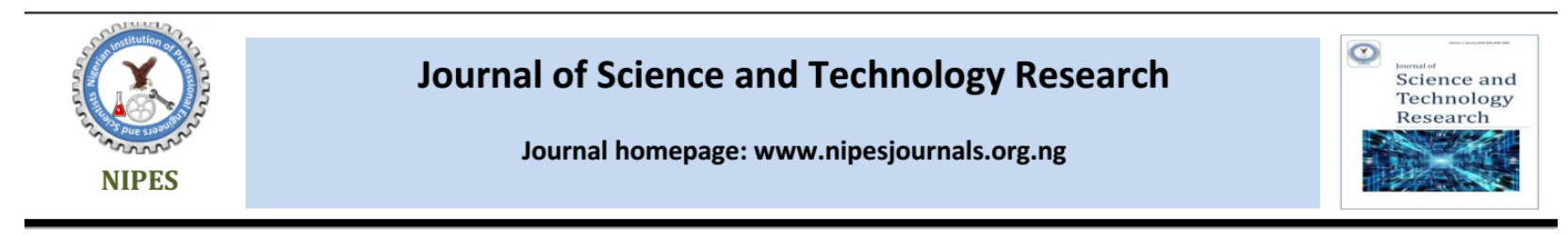

\title{
A Soft-Computing Based Course Timetabling System for Schools in Nigeria
}

\author{
${ }^{1}$ Ademiluyi, O., ${ }^{2}$ Ukaoha, K. C., ${ }^{3}$ Ndunagu, J., and ${ }^{4}$ Osang, F.B. \\ ${ }^{1 \& 2}$ Dept. of Computer Science, University of Benin, Benin City, Nigeria. \\ ${ }^{3 \& 4}$ Dept. of Computer Science, National Open University of Nigeria, Abuja, Nigeria. \\ Corresponding Author: dammy4edu@gmail.com, kingsley.ukaoha@uniben.edu,jndunagu@ noun.edu.ng, fosang @ noun.edu.ng
}

\begin{tabular}{l} 
Article Info \\
\hline Received 31 July 2020 \\
Revised 16 August 2020 \\
Accepted 17 August 2020 \\
Available online 31 August 2020 \\
\hline
\end{tabular}

Keywords:

Genetic Algorithm, Time-Tabling, Course-timetable, Soft-Computing Approach

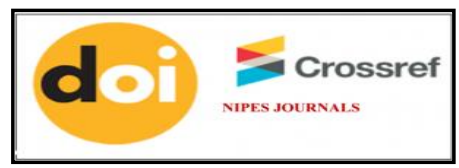

https://doi.org/10.37933/nipes/2.3.2020.28

\begin{abstract}
Timetabling, either course timetabling or examination timetabling is one of the major factor that influences the academic performance of any institutions. It's a task that varies from one institution to another depending on the identified constraints. Timetabling is a constraint satisfaction problem whereby the primary goal is satisfying the amount of constraints as much as possible. The task of generating timetable is tedious, time consuming and getting a feasible timetable is not certain. This research work provides solution to the problem encountered in generating a timetable by designing and implementing a soft computing based course timetabling system using genetic algorithm. Genetic algorithm (GA) is one of soft computing techniques in solving optimization problems and is an adaptive heuristic search which is anchored on the principle of Darwin's theory of natural selection and genetics. The system is found useful and supportive in generating timetable, as it saves the physical and mental stress undergone during manual drafting of the timetable.
\end{abstract}

https://nipesjournals.org.ng

(c) 2020 NIPES Pub. All rights reserved

\section{Introduction}

The existence of activities or events in our society is unavoidable, which in turn gives birth to the need of timetable for the planning of events. Timetable is an inventory used for the planning of an occasion or activities or a list of information which specify the times, when and where a particular event or activities occurs. Timetabling is the task of making a timetable while satisfying some stated conditions [1]. Timetabling can also be classified as a constraint satisfaction problem whereby the primary goal is to satisfy the amount of constraints as much as possible [2], [3]. Timetabling is the allocation of resources to objects while considering some constraints in order to satisfy a given list of desirable objectives near optimal [4].

Timetabling is a demanding and challenging administrative task of any academic institution, the process which varies in difficulty according to the problem size and demanding constraints depending on the academic institution. It is used to ensure allocation of scarce resources among competing entities. The effective allocation of resources is an issue that has great impact on all institutions. Timetabling is a vital and common scheduling problem in every sector, such as; education, health, agriculture, etc. Educational institutes like universities often have to deal with the classical problem of timetable scheduling every time. Academic timetabling majorly involves course timetabling and exam timetabling. 
Course timetabling is the process of scheduling a number of lecture events to different timeslots and venues within a week based on certain identified conditions [5]. Course timetable is fundamental to smooth and efficient academic delivery of any university. Educational timetable has a remarkable impact on academic system as it affects the academic performance and productivity of students and lecturers, it also determines the quality of education of any institution. It is therefore crucial for every institution, irrespective of her size to develop a quality, balanced, feasible and effective timetable devoid of clashes. Timetabling is an issue of concerns in every institution but for the purpose of this research work, this study will be limited to course timetabling system in University of Benin, Benin-City, Edo State, Nigeria.

In University of Benin, course timetabling is done manually at the beginning of every semester in each department and faculty of the institution given priority to non-clashes of lectures period for different levels of students in terms of courses, time slots and venues. This task is always assigned to the appointed timetable officer who is also an academic staff. By implication of the task being time consuming and tedious, the efficiency of such staff assigned with this task is unavoidably reduced. The manual approach of generating timetable is mostly characterized with clashes, time consuming and stressful (physical and mental stress). There are situation where a lecture is scheduled for two or more classes at the same timeslot or one lecture room schedule for two different levels or lecturers at the same timeslot.

Course timetabling was identified as a combinatorial optimization problem [6], while [7], identified course timetabling as a hard problem in combinatorial optimization domain. The nature of timetabling problems as identified by these researchers' means that the solution to timetabling problems cannot be obtained in a polynomial time which make these problems more difficult and time consuming. Presently, there is no effective solution to issues encountered in generating timetable and the time expected to solve these issues utilizing existing procedures rises as the issues developed [8]. The University Course timetabling scheduling problem is a classic problem faced by every university but due to dissimilarity in needs, constraints and preferences of universities. It is not possible to develop common and universally acceptable method and solution to solve course timetabling problem for all types of universities worldwide.

Therefore, there is a need to provide a solution to the problems associated with the manual approach of generating timetable by using soft computing technique; genetic algorithm approach to generate an optimal timetable with constraint satisfaction devoid of clashes. Genetic Algorithms (GA) is one of soft computing techniques in solving optimization problems. GA is an adaptive heuristic search which is anchored on the principle of Darwin's theory of natural selection and genetic. It signifies an intelligent use of a random search within a definite search space to provide solution to a problem [9].

\section{2. $\quad$ Related Works}

Several researchers have designed, proposed and implemented different techniques to address scheduling problems and specifically the course timetabling problems. Valdecy and Helder proposed a linear integer model for solving courses timetabling problem in a faculty in Rio de Janeiro University, Brazil for the planning of modules offered in the second semester of 2011 in the evening shift. A total of 77 lecturers were to be allocated to 302 different modules distributed over the nine undergraduate programmes. The objective function set for the proposed model was to maximize the allocation of lecturer as a function of a weight or score attributed to each of them which depends on their title while some set of constraints (hard and soft) are satisfied. The objective 
function increases; when a lecturer is allocated on one of his/her available days, the higher his/her post, the larger the increment. The objective function is decreased, if the lecturer is allocated to some day on which he/she is not available. The goal of the work which is building a model that identifies timetables that best satisfy the requirements of lecturer allocation in the university is achieved and the model was accepted by the institution's managers and the courses' coordinators. The major drawback of the model is that it cannot be used to solve large timetabling problem due to its high computational power [10].

[11] proposed and implemented a simulated annealing technique in solving the university course timetabling problems instance of Tahmidi University, Malaysia. The inputs for the system are: courses, academic staffs and facilities. Their approach spans through five stages, which are: data collection; it was achieved by conducting interviews with administrative staff, lecturers, students and data analyzed from previous semesters over a two-year period. Formulation; the existing fitness function was used to make updates on the hard and soft constraints of their problem instance. Model; the fitness function was modeled with the simulated annealing method. Testing; the algorithm was tested with their proposed fitness function. Implementation; the simulated annealing method guided by their fitness function was implemented to solve their problem instance.

[12] proposed graph colouring and integer linear technique to solve faculty course timetabling problem of University of Sri Jayewardenepura. The system uses an integer linear programming model which attempts to assign groups of course units to time periods where each group is a result of a graph colouring approach. The objective function of the model is designed to minimize the undesirability of assigning a set of course units to a time period. The researchers claimed that the model results is a feasible solution which has reduced the maximum idle time of students to three hours and it can be implemented with the lecture halls currently available in the faculty of Applied Sciences, University of Sri Jayewardenepura.

A fuzzy genetic heuristic algorithm in solving the timetabling problem of St. Xavier's College, India was proposed by [13]. GA indirect representation was used to represent the problem and heuristic local search operators were employed. Fuzzy set models are used to measure the soft constraint violation to determine the fitness of individual while probabilistic measures are used to determine the imprecision and uncertainties. The procedure for the proposed fuzzy genetic algorithm are: population initialization, fitness evaluation, population diversity, sexual selection, fuzzy controller, fuzzy crossover, fuzzy mutation and replacement. The major drawback of the proposed algorithm is that it is highly computationally intensive [13]. Sanjay and Rajai proposed and implemented a genetic algorithm to solve timetable problem of Babsaheb Ambedkar Technology University, India. The genetic algorithm is used to schedule 60 lecturers for 180 students to 5 classrooms for 5 working days weekly which is 8 hours per day and 1 hour for lunch break. A fitness function is defined and a number of constraints are stated for satisfaction. The proposed system is implemented with C++ programming language on Microsoft Visual Studio environment [14].

\section{Methodology}

The proposed soft computing based course timetabling system is a system that is designed using Genetic Algorithm (GA) approach. Evolutionary Computation (EC) is a field of computer science that uses biological processes as a model for solving problems [15].

The dataset used for the design and implementation of this soft computing based course timetabling system were 2017/2018 first semester course timetable and course allocation. The dataset was 
collected from the Department of Computer Science, University of Benin, Benin-City, Edo State, Nigeria. The population of this research work is made up of all academic staff in the Department of Computer Science, University of Benin, Benin-City, Edo State, Nigeria. Twenty-three (23) lecturers which 2017/2018 first semester courses were allocated to were selected for this work and five (5) lecture venues were also selected. The snapshot of the dataset collected are shown in Figure 1 and 2 respectively:

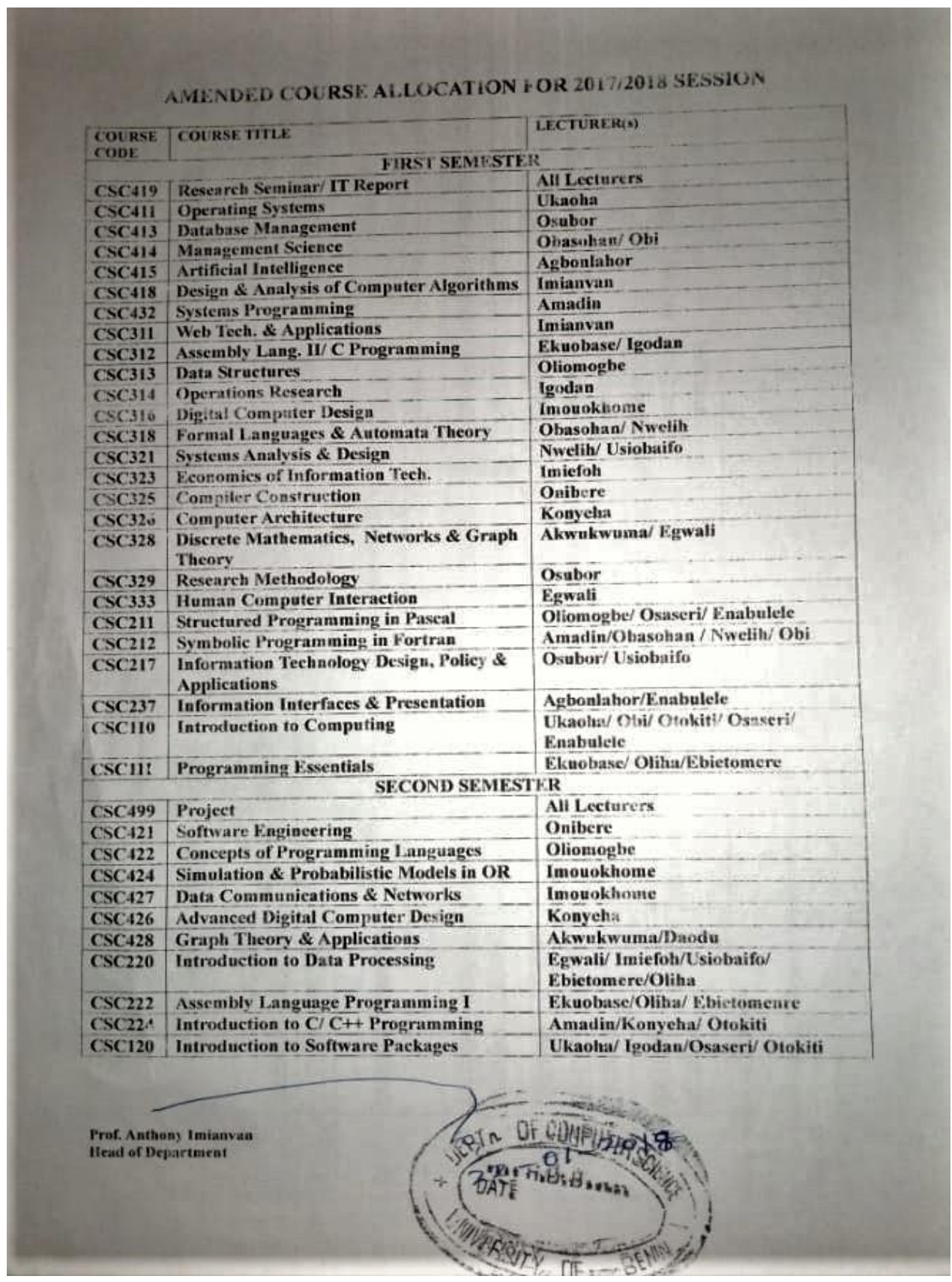

Figure 1: Course Allocation for 2017/2018 session. Source: Department of Computer Science, University of Benin, Benin-City, Nigeria 


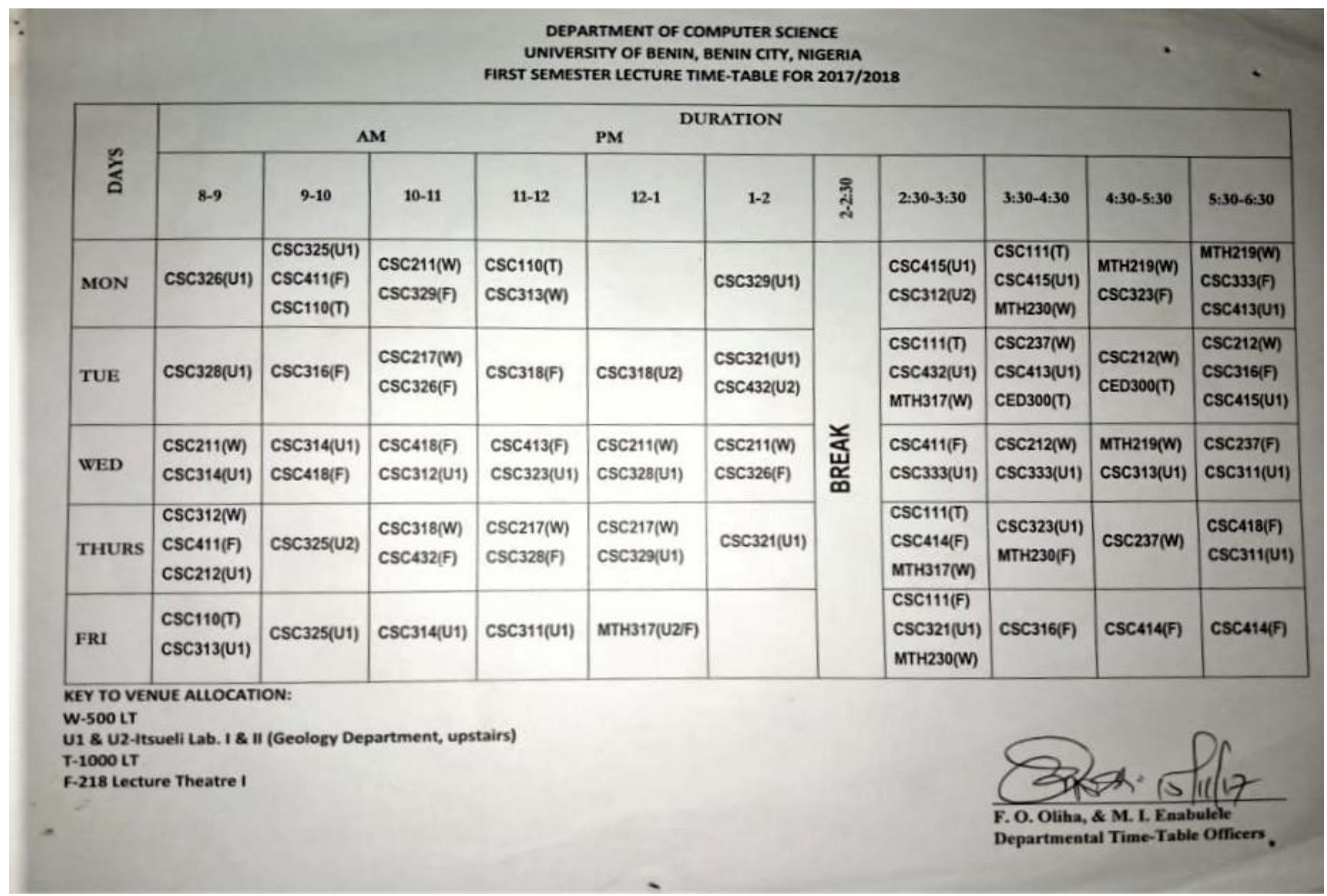

Figure 2: Course Timetable for 2017/2018 session

Source: Department of Computer Science, University of Benin, Benin-City, Nigeria

The genetic algorithm component serves as the major engine for the proposed system. The proposed system was implemented using Java Programming Language under windows 10, running on Intel Celeron. The task of allocating course to a limited period and venue in the Department of Computer Science in a way to avoid clashes is addressed by identifying and analyzing some constraints. The analyzed constraints are grouped into two: Hard Constraints (HC) and Soft Constraints (SC). HC provide operational feasibility of the schedule; $\mathrm{HC}$ are conditions that must be fulfilled in all circumstances before a particular timetable can be considered feasible. SC are desirable conditions which may or may not be satisfied, but the more SC are satisfied, the better the timetable. The constraints identified for this work are as follows:

HC1: No student should be scheduled for more than one class in a period

HC2: No lecturer should be scheduled for more than one class in a period.

HC3: No classroom should be scheduled for more than one lecture in a period.

HC4: Everyday 2:00-2:30pm is to be allocated for break.

SC1: Lectures should be evenly spread per day.

Procedure for the GA used for this work is as follows:

i. Initialize with $\mathrm{n}$ chromosomes (course timetables) 
ii. Evaluate the fitness $\mathrm{f}(\mathrm{y})$ of each chromosome $(\mathrm{y})$ in the population using the following fitness function:

$$
\text { fitness function }=\sum_{i}^{\text {Number of periods in a day }}\left(\text { period }_{\text {value }}\right)
$$

Where;

Number of periods in a day $=11$

$\mathrm{i}=1,2,3, \ldots 11$

Period $_{\text {value }}=$ timeslot value for each gene representing the hours in a day such as free period, break and course with venue of fitness 0 and 1 respectively.

iii. Repeat 3a, 3b, 3c using objective function given:

$$
\text { Objective function }=\sum_{i}^{n} \text { Constraint }_{i} \text { WeightViolation }
$$

Where;

$\mathrm{n}=$ total number of constraints

$\mathrm{i}=1,2,3 \ldots \mathrm{n}$

The objective function of the genetic algorithm procedure will determine if the timetable is feasible or not. It will determine if a constraint has been violated and number of violated constraints. If a

\begin{tabular}{|c|c|}
\hline HC1 $($ constraint 1$)=\left\{\begin{array}{l}1 \\
0\end{array}\right.$ & $\begin{array}{c}\text { Courses in one timeslot } \geq 2 \\
\text { Otherwise }\end{array}$ \\
\hline HC2 $($ constraint 2$)=\left\{\begin{array}{l}1 \\
0\end{array}\right.$ & $\begin{array}{r}\text { courses assigned a lecturer per slot } \geq 2 \\
\text { Otherwise }\end{array}$ \\
\hline HC3 $($ constraint 3$)=\left\{\begin{array}{l}1 \\
0\end{array}\right.$ & $\begin{array}{r}\text { courses assigned to a room } \geq 2 \\
\text { Otherwise }\end{array}$ \\
\hline HC4 $($ constraint 4$)=\left\{\begin{array}{l}1 \\
0\end{array}\right.$ & $\begin{array}{c}\text { every 2:00-2:30hour is assigned for break } \\
\text { Otherwise }\end{array}$ \\
\hline SC1 $($ constraint 5$)=\left\{\begin{array}{l}1 \\
0\end{array}\right.$ & $\begin{array}{r}\text { courses of same level per day } \geq 3 \\
\text { otherwise }\end{array}$ \\
\hline
\end{tabular}
hard constraint is violated the timetable is regarded as not feasible.

a. Select pair of chromosomes based on their fitness values using Roulette wheel selection method.

b. Perform crossover operation by exchanging the values of the selected parent chromosomes using Two-point crossover method. This will generate new schedule (offsprings). 
c. Perform mutation operation by changing at random the period allocation in the timetable using a mutation rate.

iv. Replace the current population with new population.

v. Go to step 3 until a desirable solution is found or the maximum number of generations is completed.

\section{Results and Discussion}

The developed system was tested by inputting all the necessary data needed to generate a timetable. Figure 3, Figure 4, Figure 5, Figure 6, Figure 7, show the various interface in the system respectively.

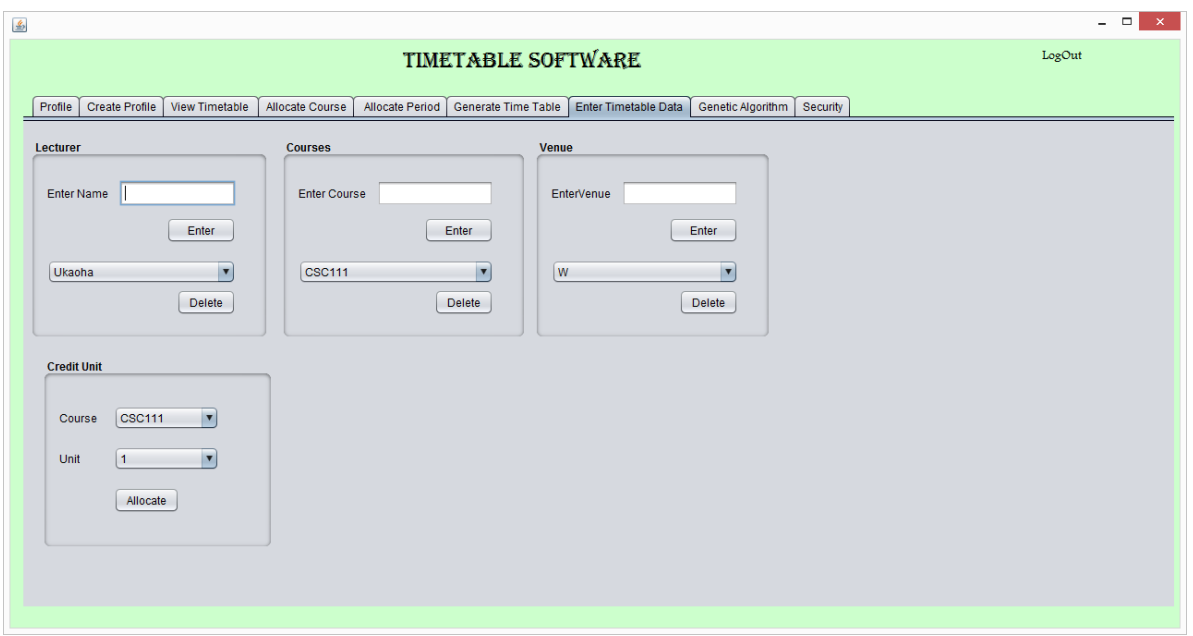

Figure 3: Timetable Data Form

The timetable data interface allows the timetable officer to input the courses to be offered with the course unit, the venues available for use and the lecturers to be engaged for the semester.

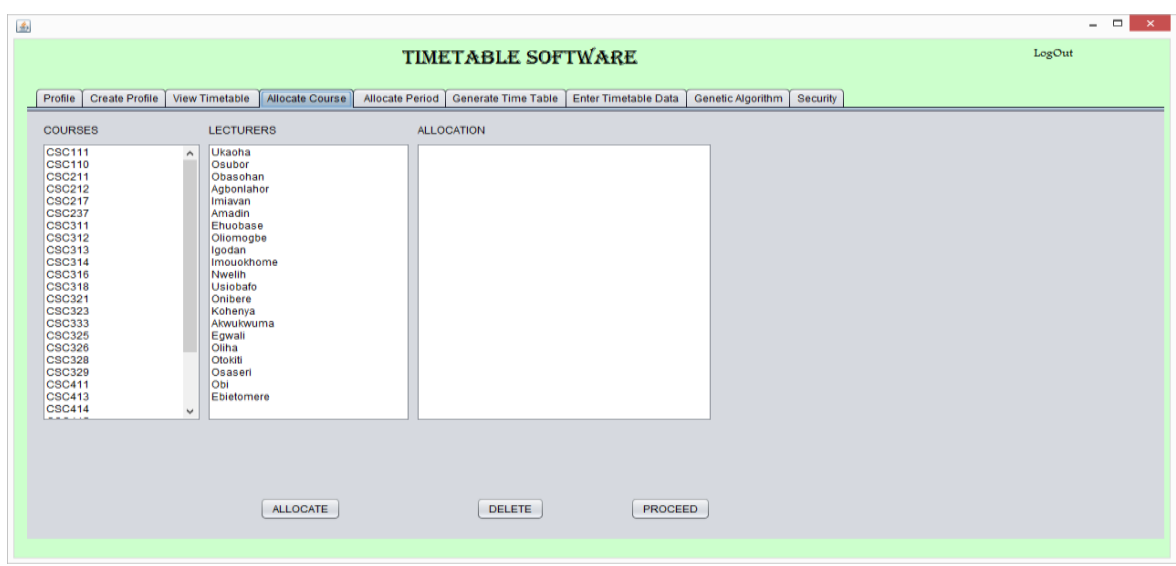

Figure 4: Course Allocation Form 
The course allocation interface allows the timetable officer to allocate courses to the lecturers.

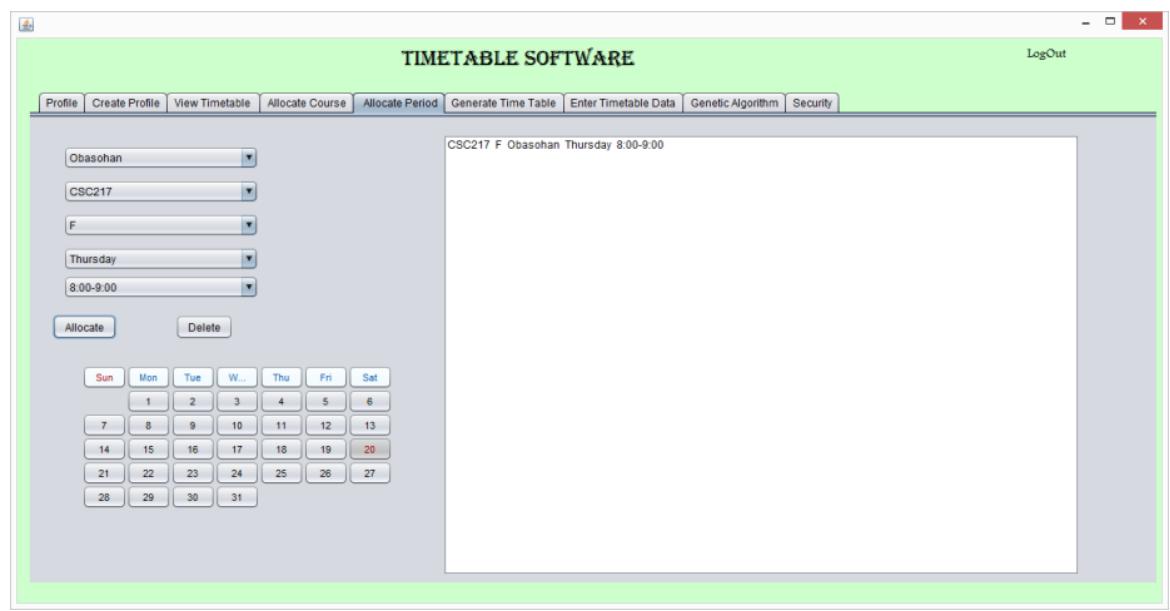

Figure 5: Period Allocation Form

The period allocation interface enables the timetable officer to assign allocated courses to venues and timeslots.

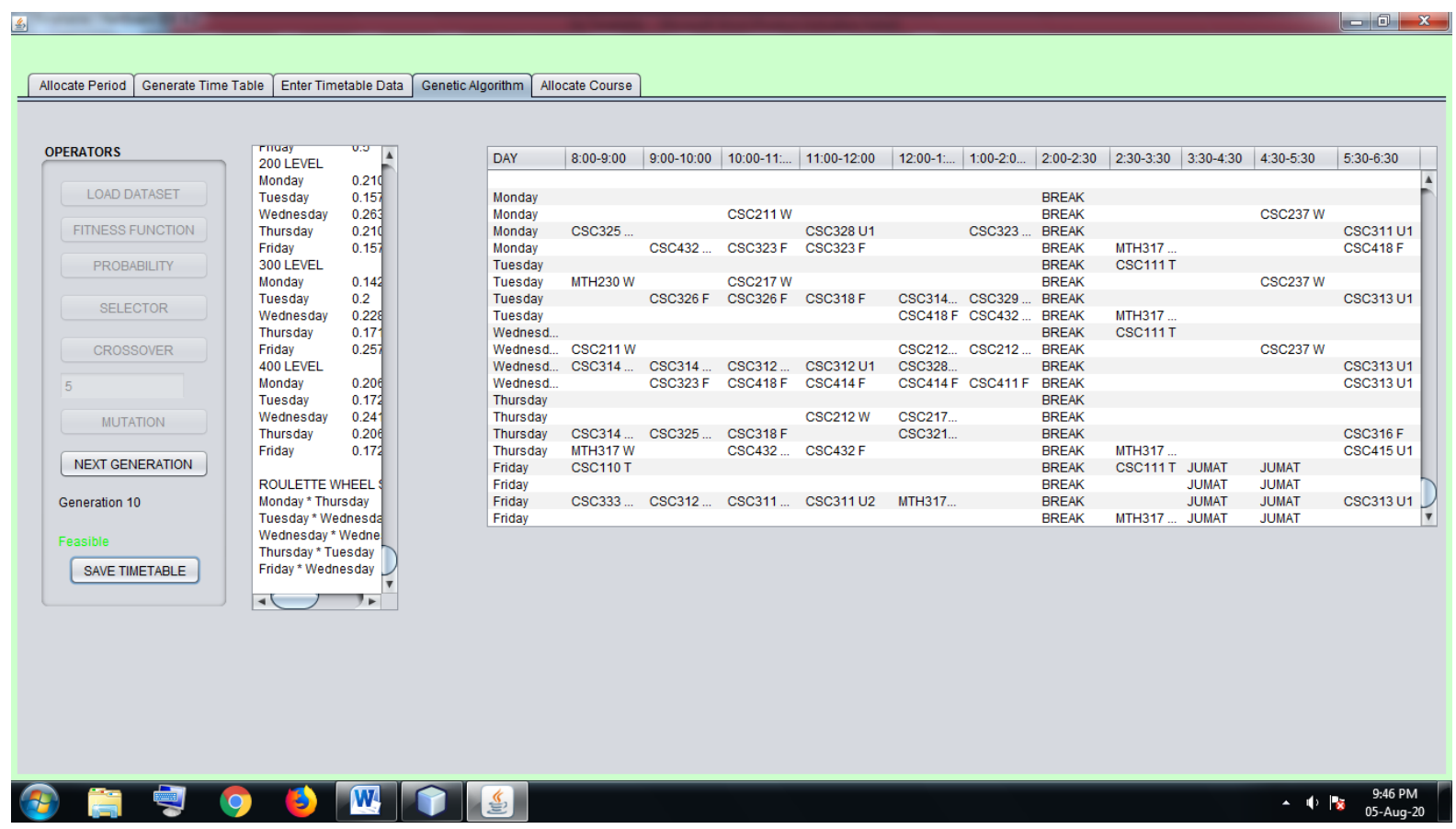

Figure 6: Genetic Algorithm Interface

The genetic algorithm interface allows the timetable officer to perform genetic operation. Here, the timetable officer continues to carry out genetic operations by selecting the genetic operators until a feasible timetable is achieved. Then the timetable officer saves the feasible timetable for timetable 
generation. The objective function of the genetic operation will determine if the timetable is feasible or not, constraint violated and number of violated constraints.

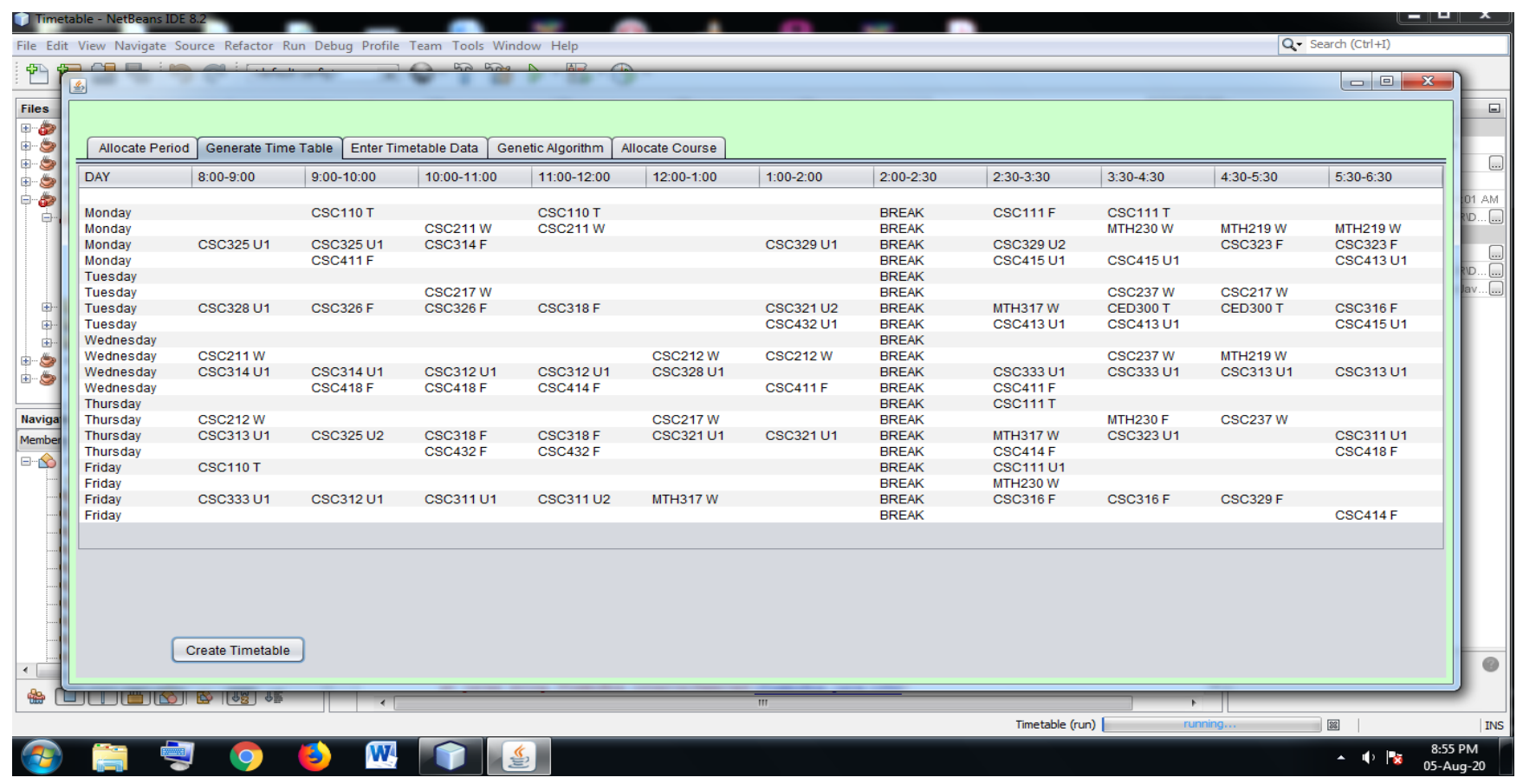

Figure 7: Timetable Generation Interface

The timetable generation interface enables the timetable officer to generate timetable after which genetic operations has been performed.

Timetabling which is classified as a constraint satisfaction problem whereby the primary goal is to satisfy the amount of constraints as much as possible [2], [3]. The generated timetable was found to be feasible in which all the identified and analyzed hard constraints are satisfied. The hard constraints satisfied are: $\mathrm{HC} 1, \mathrm{HC} 2, \mathrm{HC} 3$ and $\mathrm{HC} 4$. The generated timetable did not satisfy the soft constraints (SC1) in which the courses are not even distributed per day across all levels. Those that participated in the system evaluation testing; are lecturers in the Department of Computer Science, University of Benin, Benin-City, Edo State, Nigeria. The level of computer literacy of the lecturers who participated in the test is high. The Timetable officers of the department reported that the system was able to generate feasible timetable that is void of clashes, the task of generating timetable is not tedious as compare to the manual method of generating timetable and it will help in prompt releases of courses timetable every semester to ensure early beginning of lectures.

\section{Conclusion}

Course timetabling problem is an NP hard scheduling problem which every university tackle every semester mostly using manual method. This manual method is stressful, time wasting and generating optimal timetable free of clashes is not certain. This study was carried out using genetic algorithm to develop a soft computing based course timetabling system to reduce the intense manual effort being put into generating university timetables. A first semester timetable was used as dataset and 
optimized using genetic algorithm. The course timetabling system has the capacity to generate feasible timetable void of clashes. The system is found useful and supportive in generating timetable, as it saves the physical and mental stress undergo during drafting of the timetable manually. The future enhancement of the system could be extending the input and output sets of the system and also implementing it as a web based application.

\section{References}

[1] Dipesh M., Hiral D., Mohammed S., \& Renuka, N. (2015). “Automatic Timetable Generation using Genetic Algorithm", International Journal of Advanced Research in Computer and Communication Engineering, Vol. 4, No.2, pp.11-21.

[2] Cambazard, H., Hebrard, E., O'Sullivan, B., \& Papadopoulos, A. (2012). Local Search and Constraint Programming for the Post Enrolment-based Course Timetabling Problem. Annuals of Operations Research, 194(1), pp.111-135.

[3] Wijaya, T., \& Manurung, R. (2009). Solving University Timetabling As a Constraint Satisfaction Problem with Genetic Algorithm. Proceedings of the international conference on advanced computer science and information systems, pp.34-45.

[4] Wren, A. (1996). "Scheduling, timetabling and rostering: a special relationship?" In practice and theory of automated timetabling. Springer, pp. 46-75.

[5] Salwani, A., \& Abdul, R. (2008). "A Hybrid Approach for University Course Timetabling", International Journal of Computer Science and Network Security (IJCSNS), Vol.8, No.8, pp.9-16.

[6] Ismayilova, N., Sagir, M., \& Gasimov, R. (2007). "A multiobjective faculty course-time slot assignment problem with preferences," Journal of Mathematical and Computer Modelling, vol. 46, no.7, pp.1017-1029.

[7] Benli, O., \& Botsali, A. (2004). "An optimization-based decision support system for a university timetabling problem: An integrated constraint and binary integer programming," Journal of Mathematical and Computer Modelling, vol. 5, no.8, pp.500-510.

[8] Ebinum, W., \& Souley, B. (2017) "Resolving Timetable Scheduling Problem Based on Bio-inspired Genetic Algorithm," British Journal of Mathematics \& Computer Science, vol.21, no.3, pp.1-19.

[9] Bajpai, P. and Kumar, M. (2010). "Genetic Algorithm: an Approach to Solve Global Optimization Problems", Indian Journal of Computer Science and Engineering, Vol.1, No.3, pp. 199-206.

[10] Valdecy, P. and Helder, G. (2016). "Linear Integer Model for the Course Timetabling Problem of a Faculty in Rio de Janeiro," Advances in Operations Research, vol. 2016, Article ID 7597062, pages 9.

[11] Basir, N., Ismail, W., \& Norwawi, T. (2013). A simulated Annealing for Tahmidi Course Timetabling, procedia technology, vol.11, pp.437-445.

[12] Perera, M., and Lanel, G. (2016). “A Model to Optimize University Course Timetable Using Graph Coloring and Integer Linear Programming" IOSR Journal of Mathematics (IOSR-JM) e-ISSN: 2278-5728, p-ISSN: 2319-765X. vol.12, no.5, pp.13-18.

[13] Arindam, C. and Kajal, D. (2010). "Fuzzy Genetic Heuristic for University Course Timetable Problem", International Journal of Advanced Soft Computing Application, vol.2, no.1, pp.74-85.

[14] Sanjay, R. and Rajan, S. (2012). "University Timetabling based on Hard Constraints using Genetic Algorithm”, International Journal of Computer Applications, vol.42, no.15, pp0975-8887.

[15] Angeline, P. (1995). “Adaptive and self-adaptive evolutionary computations," Computational Intelligence: A Dynamic System Perspective, Piscataway, IEEE Press, pp.52-163.

[16] Srinivas, M. and Patnaik, L. (1994). “Genetic Algorithms: A Survey,” Computer, vol.27, no.6, pp.17-26.

[17] Ashish, J., Suresh, J., \& Chande, P. (2010). "Formulation of Genetic Algorithm to Generate Good Quality Course Timetable", International Journal of Innovation, Management and Technology, vol.1, no.3, pp.10-24.

[18] Luchian, H., Breabar, M., \& Bautu, A. (2015). "Meta-Heuristics in Optimization and Data Analysis, Springer International publisher Switzerland, DOI10.1007/978-3-319-16531-8_2. 